\title{
The Application of Constructivism: Activities for Enlivening Comprehensive English Class
}

\author{
Jing Shi ${ }^{1}$ \\ ${ }^{1}$ School of English for International Business, Guangdong University of Foreign Studies, China \\ Correspondence: Jing Shi, School of English for International Business, Guangdong University of Foreign \\ Studies, Guangzhou, Guangdong, 510420, China. E-mail: sj@oamail.gdufs.edu.cn
}

This essay belongs to the research project “ 'Data-Driven Learning' in MBA English teaching” (Project Code: 12Q21) sponsored by Guangdong University of Foreign Studies; and it is also sponsored by the Sixth Session of "China Foreign Language Education Fund" of China National Research Center for Foreign Language Education (Program Code: ZGWYJYJJ2012A37).

Received: July 23, 2012 Accepted: December 4, 2012 Online Published: December 26, 2012

doi:10.5539/elt.v6n2p63 URL: http://dx.doi.org/10.5539/elt.v6n2p63

\begin{abstract}
The Comprehensive English Course (CEC) plays a vital role in English language learning for college students in China. However, students' motivation for this course is low due to the fact that they are bored with the instructivist-based teaching environment. This paper first reviews the theories of Constructivism, and then demonstrates how to apply constructivist-based pedagogy in an instructivist-based environment by illustrating the constructivist-based activities: free writing, formative assessment, data-driven learning and sentence auction. This pedagogic proposal is not just suitable for the CEC in China, but also useful for the course where the four skills of the English language are practiced while constructivist-based teaching methods are not in use. Hopefully this proposal can contribute significantly to the undeniable need to educate students to be more informed, curious, and critical in English language teaching and learning.
\end{abstract}

Keywords: constructivism, formative assessment, data-driven learning

\section{Introduction}

China holds the largest number of English language learners in the world and has long valued language and cultural education. In most universities and colleges in China, the Comprehensive English Course (CEC) is a prescribed general education course for students, which is designed for college students to practices their all four skills of English: listening, speaking, reading and writing. In a non-English speaking country like China, students do not have many opportunities practicing English outside of class. They usually acquire vocabulary, study sentence structures and grammatical rules, and practice the four skills, only in the CEC.

Textbooks are similarly limited; they typically follow a functional, structural and content-based approach. The lessons are predictable and quite monotonous - teachers illustrate language points, give exercises for students to work on, and administer tests. Therefore, teachers do most of the talking while students listen, take notes, or give short and simple responses. Students are not motivated to perform well in the CEC because they have already had extensive exposure to this type of teacher-centered and spoon-fed approach to language instruction. In this article, I describe some activities for transforming a dull and dry lesson plan into an interesting teaching and learning experience; in fact, the suggestions I make could be applied to any EFL class in which the general aim is to improve each learner's four language skills in a content-based instruction context.

This article first reviews the theory of Constructivism, and then demonstrates how to apply constructivist-based pedagogy in an instructivist-based environment by illustrating the three main parts of my teaching process: warm-up, vocabulary teaching and sentence structure teaching.

\section{Theoretical Framework: Constructivism in Theory}

EFL teaching in China has a long tradition of instructivist-based pedagogy which relies on didactic lectures, rote 
memorization, and high-stakes exams. The instructivist-based approaches fail to trigger students' interest in EFL learning. In this article, I illustrate how I introduce constructivist-based pedagogy into the instuctivist teaching and learning culture.

Constructivism has been viewed as a philosophy and a theory of communication and in recent decades it has emerged as a dominant paradigm in education (Kaufman 2004). Constructivism in education stems from notions of cognitive and social constructivism (Schcolnik et al 2006; Kaufman 2004). The former is grounded in the work of Piaget (1954; 1955; 1970; Piaget and Inhelder 1971) and sheds light on cognitive development and individual construction of knowledge; the latter focuses on social construction of knowledge and is underscored in the work of Vygotsky (1986). The debate over the relative influence of these two approaches of constructivism on learning continues. But I believe these two approaches are not exclusive of each other; rather, they are "inextricably entwined" (Schcolnik et al. 2006).

The activities I adopt to replace the instructivist teaching and learning methods are rooted in both of these two approaches of constructivism. According to constructivist-based pedagogy, the learning process of knowledge is also the construction of knowledge. While students construct knowledge on their own, teachers are valuable helpers and propellers of the process (von Glasersfeld 1996; Duffy and Cunningham 1996). Taking these guiding principles into consideration, I can suggest several basic rules for constructivist-based teaching pedagogy in EFL classrooms. The activities in this article are in compliance with the following rules:

- These activities are learner-centered and task-based.

- Students can inductively build up their own knowledge by performing these hands-on and minds-on activities.

- These activities require communication and the exchange of ideas.

- These activities are designed to disturb student equilibrium, but then guide them on how to resolve the disturbance and return to equilibration.

- These activities encourage reflection and critical thinking by students.

- Spontaneity is important in a constructivist-based class but a sketch of the teaching plan is necessary.

- These activities provide students with external and internal scaffolding. External scaffolding "supports students' acquisition of knowledge by breaking down tasks into comprehensible components, modeling, coaching, providing feedback, and appropriating responsibility for learning to students"(Kaufman 2004). Internal scaffolding "engages students in reflection and self-monitoring" (Kaufman 2004).

\section{An Analysis: Constructivism in Application}

The students I teach are Business English majors in a prestigious university specialized in foreign language teaching in South China. In their first two years, the CEC is a compulsory course designed to help them lay a solid foundation for their future study, especially the courses of business taught in English when they are in the third and fourth years at college. The textbook they use is content-based and covers a wide range of topics which are not necessarily related to business. I take Text 1 of Unit 2 in Book 1, titled "Learning to Learn" as an example to illustrate the way I carry out the constructivist-based activities. My teaching procedure is summed up in Figure 1 below. 


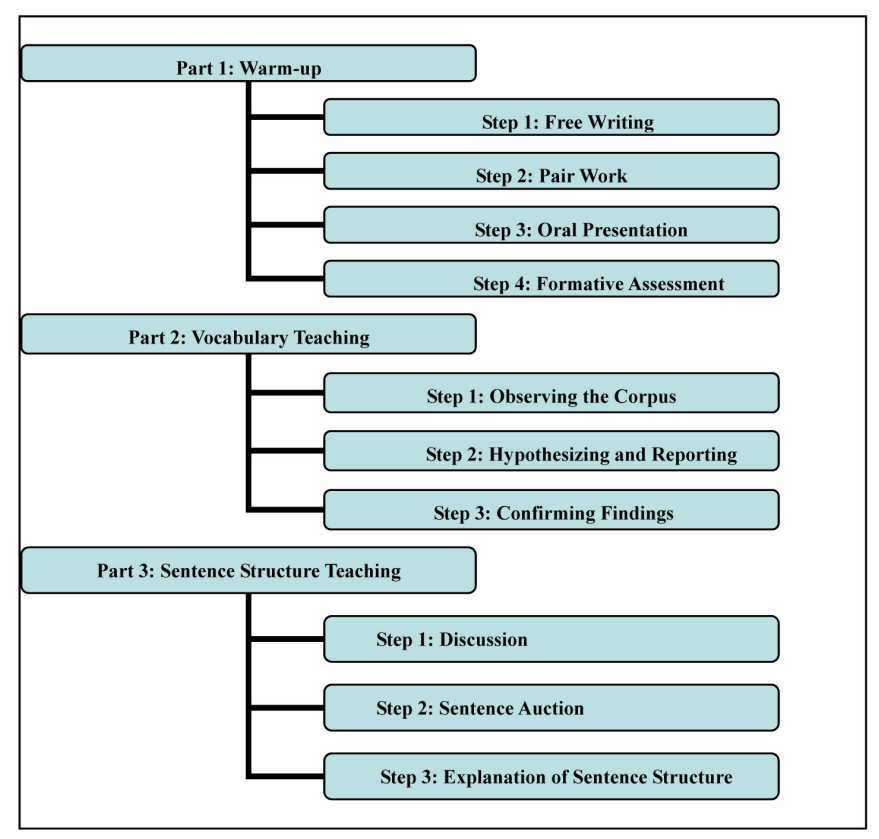

Figure 1. A lesson outline ( 2 class hours)

\subsection{Warm-up}

Students are required to write on a given topic which is related to the content of the unit with a time limit of 5 minutes. In this case, the topic is relevant to the theme "Learning to Learn" (See Figure 2). The main points students have to cover in their compositions are stated clearly, giving students "external scaffolding."

\section{Something That You Don't Know but Would Like to Learn}

You have to describe:

- Why you want to learn this

- How you would learn it(or how you would start to learn this)

- Explain what difficulties you think you might have when learning this

Figure 2. The topic for free writing

Students brainstorm and then jot down their ideas. Writing, as an output process, is regarded the most difficult of the four language skills, since it requires a lot of practice to do well. As a result, writing is an important tool for measuring a learners' foreign language proficiency. Also, Writing enables students to focus their attention on language forms. According to Willis and Willis $(2007,117)$, "speaking is a real-time activity, in which there is normally no time for careful consideration of language. Writing, on the other hand, allows time to think about language."

However, students are not allowed to write non-stop without time control: they are required to complete their writing within 5 minutes. The time limit pushes students to think in the target language instead of resorting to word-for-word translation of their mother tongue.

In writing, students reflect on what they know and what they do not know about the topic. The activity encourages them to draw on their existing scaffolding and become more self-reliant. Teachers should be thoughtful in selecting topics for this exercise: topics should be closely relevant to the theme of the unit and should be ones to which students can personally relate and respond. This type of hands-on, minds-on exercise, which allows students to actively practice the major language skill of writing rather than passively receiving information, ensures students' involvement in class. 
Most students in China are afraid of losing face in public. Making an English presentation or giving an English speech tends to make them feel unnecessary pressure. Therefore, pair work is an ideal arrangement for class activities, since it can relieve their anxiety and help them express their ideas more freely (Lytovchenko 2009).

After the quiet writing comes the process of a classroom of students reading aloud their compositions. I adopt the method suggested by Lytovchenko $(2009,25)$, asking the students in one row to turn around and talk to the students sitting in the row behind them. In pairs, students share with each other their free-writing compositions. They may help their partners with the diction, grammar, and structure of the compositions, which enables the students to move from focusing their attention on meaning to focusing their attention on language use. Sharing their writing with a classmate is disturbing for the students, but by working together, the students resolve their disturbance and return to equilibrium. The pair work is viewed as a rehearsal for students before delivering their compositions in front of the class, making them less anxious and more excited about the idea of giving an oral presentation.

While they are doing the pair work, I stroll around the classroom to coordinate the activity, but only offer help if necessary. Students usually have problems in: expressing their ideas accurately in English, often asking the correct English equivalents for the words in Chinese (It is unavoidable for students to think in their mother tongue from time to time, especially when they are still of the intermediate level); being confused about the grammar; or trying hard to ensure that they choose the word precisely.

Two students are chosen randomly to give oral presentations to the whole class and the other students have to engage in the presentations by filling out a form which is designed according to the principles of formative assessment (See Appendix). Formative assessment, in contrast to summative assessment which occurs at the end of an instructional period and aims at capturing the results of instruction, is administered before completion of a course and has a much closer relationship to instruction because their results feed back into classroom teaching (Poehner 2007; Bachman 1990). The formative assessment I conduct is an indispensable part of the learning process. It is an ongoing, development-oriented process of collaborative engagement that reveals the underlying causes of students' performance problems and helps them overcome those problems.

In this case, assessment is no longer a formal interaction between a teacher and students as usual, but an informal interaction among students. Students are asked to take down the main ideas of the speeches of the two presenting students. They are also expected to give constructive comments on presenters' performances. At the end of their presentations, one of their classmates and I will ask each of them two questions concerning their speeches and they are required to give answers directly. The Q\&A session enables presenting students more engaged in their speeches: they should have a clear picture about what they are presenting instead of reading out the speeches mechanically. I will also give comments on their performances later on. If condition permits, I will record the whole process of their presentations and Q\&A sessions by using the digital camera. After class, I will send them a copy of the video clips and they can have a visual-audio record of their performances. It is much easier for them to get to know where their strengths and weaknesses lie by using visual-audio records.

Each student has at least two opportunities to present their compositions in one semester and receive feedback from their peers and me. The frequent feedback helps students reflect on their strengths and weaknesses in language skills not only at the end of the course, but also during the learning process. The feedback forms are filed in each student's portfolio. Students can keep track of the progress they have made by reading this portfolio. They can also compare the comments with the video clips of their performances, noticing the gap between self-awareness and others' opinions. This new form of assessment is dependent on constructivist-based pedagogy that instills an increased sense of responsibility and ownership on the part of students.

\subsection{Vocabulary Teaching}

The main method of vocabulary teaching and learning is usually the Present-Practice-Produce (PPP) mode: teachers present the pronunciations, spellings, forms, meanings, collocations, etc., of English words and expect students to memorize them. Most of the students find the PPP mode painstaking and ineffective. Because of the negative effects of the PPP mode, I prefer to use the Data-Driven Learning (DDL) approach, which is based on the Observe-Hypothesize-Experiment (OHE) mode. The advantage to this approach is that students are no longer passive recipients of knowledge; instead, they take responsibility for their language learning, with the teacher in the role of a facilitator.

According to Tim Johns (1991, quoted in Hadley 2002) the proposer of DDL theory, "Language learner is essentially a research worker whose learning needs to be driven by access to linguistic data." In the DDL 
approach, students are exposed to a large quantity of authentic language materials and they have to find out the language patterns themselves rather than simply being lectured on the correct rules for using the words. Typically, DDL involves accessing vast databases of corpora with software programs called concordancers. Concordancers can help users access a large quantity of databases, analyzing different language patterns, and summarizing the general rules for using words. It is powerful, but it is not easy to be a know-how at it.

For many EFL teachers who are not experienced in using concordancers, it's challenging for them to adopt the DDL approach. Therefore, I believe a more user-friendly online corpus query system can play a vital role in the application of DDL approach. The corpus query system I introduce is "Sketch Engine (SkE)" which provides word sketches: corpus-driven summaries of words' grammatical and collocational behaviors. Even the teachers who have never heard about "corpus linguistics" find SkE easy to use. Teachers can register for an account on the SkE website and have a one-month trial without any charges. They can conduct the DDL approach to teach vocabulary by using SkE. The procedures of vocabulary teaching are as follows:

- The target words are displayed in a format called "keyword-in-context (KWIC)"- the key word is put in the middle of the sentence and highlighted, which enables students to focus quickly on the main item of study. Students may find the sets of fragmentary KWIC lines incomprehensible. Then they can click on the lines to get complete sentences.

The teacher can have the findings printed out as handouts and distribute them to students in technologically-disadvantaged classrooms.

- Students can discover the different usage, such as lexicalized "chunks" or collocations, of the target words by reading the KWIC lines.

- Students work in pairs to exchange their hypotheses about words' usage. I will stroll around to see whether they have any problems in using SkE or if they can understand the sentences when there are quite a few words which are beyond their level appearing in the sentences.

- It is necessary to let students know that it is understandable if they cannot figure out the meaning of the sentences sometimes. The sentences in the corpus are from different kinds of resources, and the words and expressions are inevitably incomprehensible for them from time to time.

Some students are selected to report on their findings/hypotheses to the class. They also need to give evidence to support their findings. Students are encouraged to report as many findings as possible, be it right or wrong.

- Other students and I listen attentively to their findings/hypotheses and give our own opinions about the usage of the words and also the evidence to support our viewpoints. It is possible that we cannot reach consensus and hence a heated discussion. We take down our disagreement and move on to the next word. We refer to our notes again in the next step.

- Students are asked to get word sketches of the target vocabulary using British National Corpus (BNC) in SkE. In contrast to some complicated concordancers, students just type in the word, clicking "get word sketch" on the screen and they can get grammatical and collocational summaries of the word.

- Students can acquire more specific knowledge of the words (such as synonyms or antonyms) by using the "Thesaurus" function, accessed by clicking the button "Show Similar Words". The differences between the target word and its synonym are demonstrated clearly if students click "Sketch-Diff". These two functions can provide students with more depth of the word's knowledge.

- The final step is for students to compare their hypotheses with the word sketch. Furthermore, they can consult a dictionary to confirm their findings. Students have the opportunity to get access to a large quantity of authentic language materials and they try to generalize the words' usages by using SkE and dictionary. This "bottom-up" constructivist-based process is an effective replacement for the "top-down" instructivist-based process.

From my observation, compared with the instructivist-based PPP mode, in which students just take notes and practice what they have learnt rigidly; the constructivist-based OHE mode engages students to find out the usage of the words on their own. The DDL approach, based on the OHE mode, is very popular with students and they find it effective. Furthermore, SkE is a simple and convenient tool for both teachers and students who are not necessarily being experts in "corpus linguistics". 


\subsection{Sentence Structure Teaching}

The conventional method for teaching sentence structure is uninteresting and ineffective: teachers stand at the front of the classroom, analyzing sentence structure in detail, giving examples, and generalizing grammatical rules; while students take notes and receive the information passively. We often notice students dozing off in class when teachers are lecturing grammatical points about sentence structure.

My goal is to transform this monotonous teaching method into an interesting teaching and learning interaction. I adapted an activity called "sentence auction" from Folse (2008) and use it in my class. The "sentence auction" activity was originally designed for teaching vocabulary, but I believe it can be useful in sentence-structure teaching. Since Folse did not give detailed explanation about how to undertake this activity, I have re-designed the "sentence auction" activity to satisfy my teaching objectives, and I have found that it does work out effectively. This part of teaching has long been considered the most boring for students and painstaking for teachers, but with the introduction of the "sentence auction" activity, students have shown great enthusiasm in learning sentence structure.

In brief, I auction sentences which are not directly selected from the text, but are closely related to the important sentence structures used in the text. The goal for students is to buy as many correct sentences as possible. First, I find out all the important sentence structures in the text, and then consult the Chinese Learner English Corpus (CLEC) (Gui 2003) to check out the commonly-made mistakes of Chinese English learners. CLEC is a learner corpus which reliably records the interlanguage development of a representative group of learners. The typical errors found in it have implications for the selection of sentences and the "coining" of "grammatically-wrong" sentences which are used in the auction. I believe there are many other corpora of English language learners in countries where English is used as a foreign language.

Second, the sentences for auction to the students are listed on Powerpoint (PPT) slides. There are ten sentences in total, and on each of the slides are two sentences.

Third, students are divided into study groups, with four students in each group. They have a discussion about whether they should auction a particular sentence or not. According to Vygotsky (1978), from a sociocultural lens, learning is socially situated activity. Higher cognitive functions appear first on the social plane, and only later on the psychological plane. Students internalize knowledge by working in groups. Groups are not just a convenient way to accumulate the individual knowledge. Students can be both novice and expert at some point, which helps them construct their knowledge through interaction with each other.

Fourth, specially-made paper money has to be prepared: one $\$ 15$ bill, four $\$ 10$ bills, four $\$ 5$ bills, ten, $\$ 2$ bills and five $\$ 1$ bills, totaling $\$ 100$ for each group. The bid for each sentence starts at 10 dollars, and they need to add at least 10 dollars for every bid. As is the case with Folse's method, there is no penalty for buying wrong sentences and there is no credit for leftover money.

Fourth, the sentences for auction are shown on the slides one by one. Students have 3 minutes to have a discussion and decide whether they should bid for that sentence or not. Students participate in the discussion enthusiastically as they all want to be the winning group, purchasing the highest number of correct sentences. I am only the timer who makes sure the auction is conducted smoothly without providing any suggestions or hints for them.

Fifth, at the end of the auction, I announce which sentences are correct and which ones are incorrect and give detailed explanations of the language points involved. Students usually listen to the explanations attentively as they are eager to know whether they are part of the winning group - the group with the highest number of correct sentences. Very often a time, students challenge my explanation of language points and ask for more examples. In doing so, students acquire more language knowledge than learning it by rote memorization.

\section{Conclusion}

It is no exaggeration to say that students in China frequently have a negative attitude towards the CEC. Nevertheless, they attend this course because: first, it is usually a compulsory course and they need to obtain the credit to get the degree; second, they are obliged to pass a series of English proficiency exams.

Students in general will have low or even no motivation for this course if we undertake it in the conventional instructivist way. "Reform" is a slogan having been shouted for decades by English teachers and experts in China. I believe the application of constructivism in the CEC can be greatly beneficial. The three parts of my teaching procedure described above: warm-up (composed of free writing and formative assessment); 
corpus-based vocabulary teaching; and sentence auction are engaging and interactive tools which bring a lot of fun to this course. From my observation, students have higher motivation in attending this course than before and they are no-longer exam-oriented: they simply enjoy the process of English language acquisition. This pedagogic proposal is not just suitable for the CEC in China, but also useful for the course where the four skills of the English language are practiced while constructivist-based teaching methods are not in use. I hope that my proposal can contribute significantly to the undeniable need to educate students to be more informed, curious, and critical in English language teaching and learning.

\section{References}

Bachman, L. F. (1990). Fundamental considerations in language testing. Oxford: Oxford University Press.

Duffy, T. M., \& D. J. Cunningham. (1996). Constructivism: Implications for the design and delivery of instruction. In The handbook of research for education and technology. Indiana University.

Folse, K. S. (2008). Six vocabulary activities for the English language classroom. English Teaching Forum, $46(3), 12-21$.

Gui, S. C., \& H. Z. Yang. (2003). Chinese learner English corpus. Shanghai: Shanghai Foreign Language Education Press.

Hadley, G. (2002). An introduction to data-driven learning. RELC Journal, 33(2), 99-124. http://dx.doi.org/10.1177/003368820203300205

Kaufman, D. (2004). Constructivist issues in language learning and teaching. Annual Review of Applied Linguistics, 24(3), 303-319. http://dx.doi.org/10.1108/17504971111121919

Lytovchenko, I. (2009). How to make upper-level university English classes more interactive. English Teaching Forum, 47(2), 24-29.

Piaget, J. (1954). The construction reality in the child. New York: Basic Books.

Piaget, J. (1955). The language and thought of the child. New York: Meridian.

Piaget, J. (1970). The science of education and the psychology of the child. New York: Basic Books.

Piaget, J., \& B. Inhelder. (1971). Psychology of the child. New York: Basic Books.

Poehner, M. E. (2007). Beyond the test: L2 dynamic assessment and the transcendence of mediated learning. The Modern Language Journal, 91(3), 323-340.

Salsbury, T., \& C. Crummer. (2008). Using teacher-developed corpora in the CBI classroom. English Teaching Forum, 46(2), 28-37.

Schcolnik, M., S. Kol, \& J. Abarbanel. (2006). Constuctivism in theory and in practice. English Teaching Forum, 44(4), 12-20.

Von Glasersfeld, E. (1996). Introduction: Aspects of constructivism. In Constructivism: Theory, perspectives and practice. ed. C.T. Fosnot, 3-7. New York: Teachers' College Press.

Vygotsky, L. S. (1978). Mind in society: The development of higher psychological processes. Cambridge, MA: Harvard University Press

Vygotsky, L. S. (1986). Thought and language. Cambridge, MA: M.I.T. Press.

Willis, D., \& J. Willis. (2007). Doing task-based teaching. Oxford: Oxford University Press. 


\section{Appendix: Formative Assessment Work Sheet}

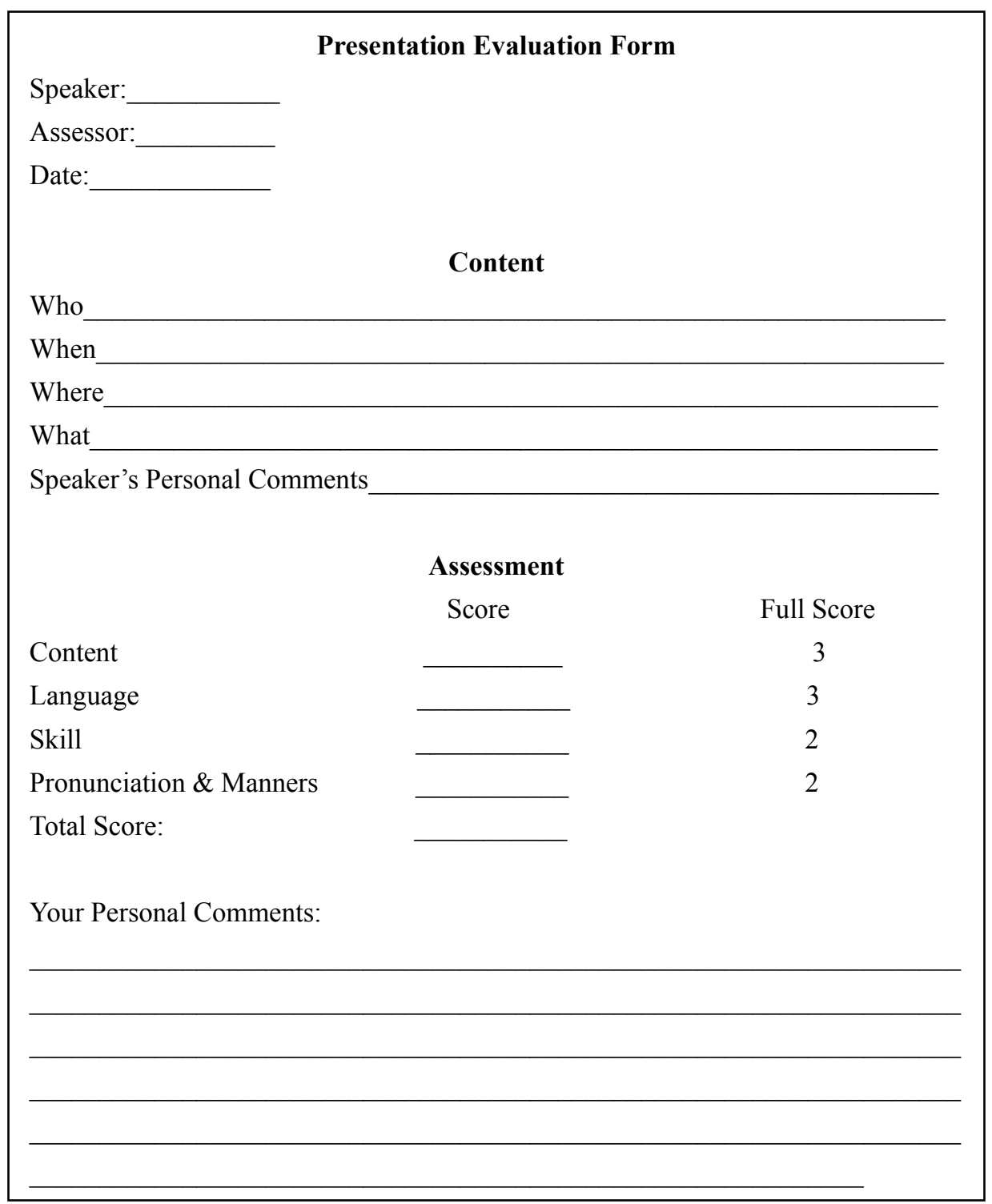

